\title{
Using Augmented Reality and Location-Awareness to Enhance Visitor Experience: A Case Study of a Theme Park App
}

\author{
Cheng Man Chan*, Sian Lun Lau*† \\ * $\dagger$ Department of Computing and Information Systems \\ $\dagger$ Research Centre for Human-Machine Collaboration \\ School of Science and Technology \\ Sunway University, Malaysia \\ 17057696@imail.sunway.edu.my,sianlunl@sunway.edu.my \\ School of Science and Technology \\ Sunway University, Malaysia \\ sianlunl@sunway.edu.my
}

\begin{abstract}
Mobile travel has become a significant trend due to the emergence of smartphones and mobile technology. Existing researches show that the integration of location-based services (LBS) is potentially adding significant values to the mobile tourism industry. The purpose of this study is to develop a location-based mobile application for theme park visitors to enhance their visiting experience. The application of locationbased solutions such as interactive map, push notification services with geofencing and augmented reality tour guide will be involved in this study. Google Map SDK for Android, Google ARCore Sceneform, GeoFire and SQLite methodology is adopted to build the application. An online survey is conducted to evaluate the user acceptance for the mobile application by sending Android Package Kit (APK) to the users. The result shows that majority of respondents had positive attitude towards the application and agreed that the application will enhance their park visiting experience. The conclusion can be drawn that the application can be further improved with features which contributes to the digitalization of outdoor parks or other fields in mobile tourism.
\end{abstract}

\section{Introduction}

Mobile application has been an integral part of our every day lives for over a decade and transformed the way people communicate, manage and perform daily task [1]. According to [2], the worldwide adoption of mobile has exceeded 500 billion users while 194 billion apps are downloaded in 2018 and this number is projected to increase rapidly every year. As a modern and fast developing segment in the global Information and Communication Technology (ICT) industry [3], the development of mobile application has become more and more mature. Mobile applications have evolved from the early basic applications to multi-platform applications that cater for various types of services to smartphone users as well as reshaping the nature of different businesses including the travel and tourism industry.

Based on [4], the global market of digital tourism industry has reached $\$ 694.41$ billion in 2018. Statistics states that the market coverage of Android travel app has occupied for $95.7 \%$ [5] while iOS travel app account for $37.79 \%$ globally [6]. The emergence of mobile technology development has transformed mobile device as an essential tool to assist in the pre-visiting, on-site visit and post- visiting of visitor's tourism experience [4] [7]. As an illustration, visitors can check the weather forecast before they go on a trip, view navigation route from their handheld devices during the trip and share their pictures taken to their social media account after the trip. Results like [6] shows that $88 \%$ of travellers think that to have access to all their favourite contents in a single app will be useful for them during the travel.

One of the major reasons why mobile apps are transforming the tourism industry is due to the presence of location-based services (LBS) that enable companies to provide on-demand services to travellers on the move $j \mathrm{r} 5 \dot{i}$ [8]. Several researchers emphasised that the functionalities of LBS include location tracking, information searching, navigation and routing, language localization, live notification for safety and emergency issues have contributed to the emergence of mobile tourism [8] [9]. Besides, mobile technology like augmented reality (AR) has been popularly adopted in the tourist industry to enrich the visitor experience. Mobile augmented reality system enables visitors to interact with innovative features and get familiar with unknown environment in an enjoyable way [10]. Studies pointed out that the visitor experience is one of the mainstays which drives the revisit intention of visitors for a destination [11].

This paper intends to investigate and present design and development of a prototype mobile tourism mobile application that incorporate LBS and AR for a theme park. This application aims to enhance the visiting experience of the theme park visitors. The application intends to overcome limitation of paper map and also improve visitor engagement during one's visit to the theme park.

The structure of the paper is as follow: Section 2 presents related work and discussion the requirements of the application. This is followed by Section 3 where the design and implementation of the application are elaborated. Evaluation results are presented and discussed in Section 4 and the paper is concluded in Section 5. 


\section{Related Work}

According to Lim [12], mobile tourism applications can be classified into three categories: tour guide companion app, recommendation system app and new mobile service app. Tour guide companion apps are mobile apps which present essential information for a place of interest. At the same time, these apps also provide interactive and personalised contents to guide visitors through their visiting journey. Visitors are allowed to engage with the mobile app by exploring the functionalities and features of the app such as gaining a quick overview of the place through an interactive map, gaining interesting information through multimedia contents as well as locating themselves with mobile positioning technology such as Global Positioning System (GPS).

An example of the tour guide companion apps is The Railway Museum App from Japan [13]. The application shows the overview of the museum with a floor map and labels the places of interests with markers. Besides, the application shows a list of attractions and visitors can click on it to view detailed information such as history, explanation and pictures. Apart from that, recommendation system apps are the mobile application that allows visitors to plan and pick a suitable services option for their visit [12]. The system will provide recommendations to visitors by calculating their preferences based on their profiles or current geo-location. The recommendation feature is ubiquitous in hotels, sightseeing, dining, tour plans and transportation apps. Research which examined on tourists' attitude towards proactive recommendation system [7] has shown that most participants follow the smartphone application's recommendation for their visit.

Location-based service (LBS) or geo-location is defined [8] as an information service that can be accessed via a mobile device and transmit data simultaneously based on its current geographic location. LBS uses real-time geographical data from a mobile device to provide relevant information, entertainment or security at the right time, at the right place. Researcher illustrated [14] that LBS is the intersection technology between Geographical Information System (GIS), Internet and mobile device. LBS are commonly made through the Global Positioning System (GPS) from a smartphone or Global Navigation Satellite System (GNSS) technology which uses satellites to transmit autonomous geo-spatial positioning. However, LBS also has its weaknesses to be adopted in an indoor environment and limitations on vertical distance. The applications of LBS in the mobile tourism industry are discussed in this study.

The map is one of the essential elements for visitors as a visual communication tool to explore a new city or region by providing information about the place, navigating visitors in the geographic area and helping visitors to decide on journey planning. Traditional paper map today is suggested to be digitised and replaced with an interactive map which is widely adopted in the mobile tourism industry together with LBS to provide better visitor experience [9]. Interactive mapping refers to the digital map that allows users to zoom in and out, move around, identify specific elements, get underlying data, generate reports or select visualised information on the map. [15] categorised interactive map as one of the products of cartographic interaction which refers to the dialogue between a human and a map with a computing device as mediator.

Augmented reality (AR) is the technology that displays computer-generated content directly or indirectly to a real world environment in real-time [16]. Over the years, the implementation of AR technology has altered the tourism industry. [17] mentioned that the AR technology is adopted as an instrumental system to satisfy visitors' demand by providing them more information, entertainment and guidance ubiquitously as well as bonding strong relationships with their mobile customers. Besides, AR is taken as an advertising and new marketing communication medium to help tourist organisations and professionals to expand their market audience as well as increasing brand awareness [17]. There are four main types of augmented reality which are marker-based, markerless, projection-based and superimposition-based. Common examples of the AR adoption in different tourism fields, including museums, aviation and sightseeing, focus on the marker-based AR, markerless $\mathrm{AR}$ and superimposition-based AR.

Marker-based AR or image recognition-based AR is the augmented reality technology which requires a marker in the real environment where the augmented object is shown when the marker is focused and detected. Some examples for the AR marker are $2 \mathrm{D}$ images and $\mathrm{QR}$ code. When a marker is recognised, the augmented contents will replace the marker on the device screen. Although a user can interact with augmented content, marker-based AR still has its limitation. As the augmented reality relies on the physical marker where the user is not able to access the AR content if there are no marker or the marker is damaged.

Unlike marker-based AR, the markerless AR provides more flexibility as the application does not rely on a physical target. Instead, the markerless AR works by scanning the surrounding of the user's environment. User is required to look for a flat surface to place the AR objects, and when a suitable surface (plane) is detected, the AR content is ready to show up on the user's device. Markerless AR is widely adopted in the tourism industry, primarily used as a location-based technology to help tourists in their journey. Location-based AR is the subcategory of markerless augmented reality. It works by detecting a user's location from the GPS of the device and adding a virtual object on the screen. Location-based AR is suitable to be adopted in the tourism industry, such as providing attraction information or guiding tourist to a destination because of its flexibility. A superimposition-based AR replaces the reality view with an augmented view. The real-life object is scanned and recognised, and the virtual content will be overlaid in the augmented view.

In conclusion, there are many ways for mobile technology to enhance the visitor experience throughout their travel journey. Several researchers [11], [18] emphasised on the importance of customer engagement and customer 


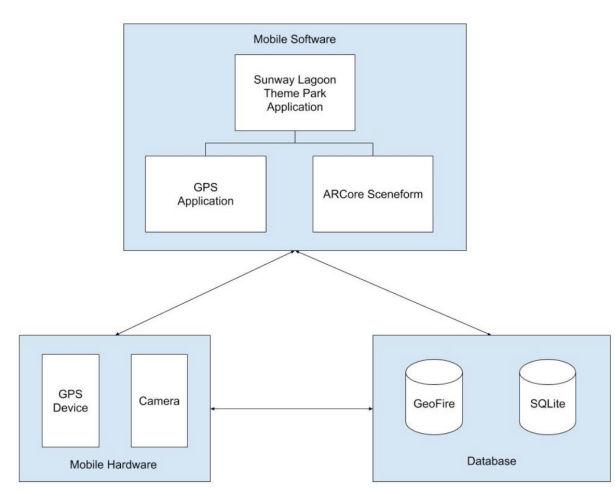

Figure 1: The system architecture

satisfaction towards visitor experience and visitor experience is one of the major influencing factors which determines a visitor's revisit intention. For this project, as it is mainly focused on location-aware functionality, the location-based AR method is adopted to display augmented content on the user's device based on their current location.

\section{Design and Implementation}

In order to design the application, system requirements have been gathered based on the analysis outcome of the literature review. As discussed in Section 2, interactive map, push notifications will be essential features in a mobile visitor application. Augmented Reality (AR) has high potential, so the project will explore markerless/location-based AR to validate its suitability. As a result, we designed the prototype application based on the following system architecture:

The map on the application will obtain the latest live location by acquiring the information from the GPS device. Similarly, the camera will be another input source to enable the use of markerless AR. Data will be stored in the databases. The SQLite database is used to store static information such as name, description, category and the location of the attractions. Firebase Realtime Database from Google is used to store key-value pairs of user's location. This function allows the use of its publish/subscribe feature to allow triggering of events to allow the app to react once a new location is updated. In this way, geofencing can be implemented for the application.

The application is designed to have six screens - the welcome screen, home page, attraction list, attraction detail, interactive map and AR guide. The user is greeted with the welcome screen every time they launch the application, and then the screen navigates to the home page, which is the main screen of the application. From the home page, the user can navigate to the attraction list page, interactive map and the AR guide page. While from the attraction list page, the user can navigate to the attraction detail page, which shows the attraction's information details. From the attraction, detail page user can also navigate to the interactive map where the interactive map is also designed to have a function to navigate to the attraction list.

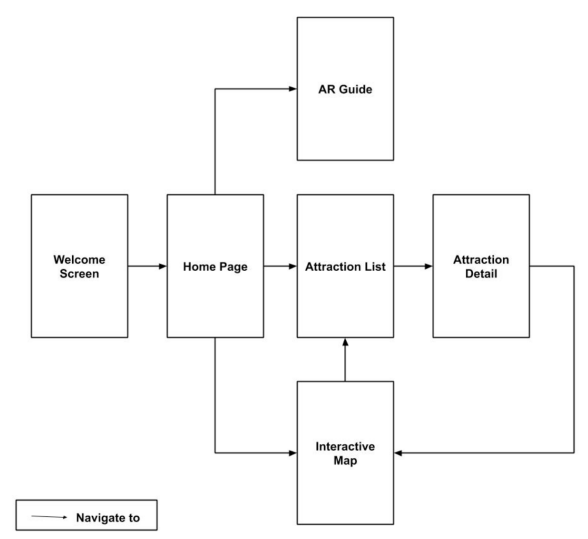

Figure 2: The system architecture

The application is developed on Android Studio 3.4. Main libraries used are Android Map (and Google Map) and ARCore. An image-based custom map is placed as an overlay on top of the Google Map layer. This allows the application to display the attractions of the theme park. Towards the end of the development, A test case has been designed to perform tests on the interactive map and attraction list, AR guide as well as push notification with geofencing. Finally, a user acceptance test is carried out as a survey to collect feedback from users on their experience with the application.

A few screenshots of the finish application can be seen in Figure 3 and 4. The former shows the main screen and the attraction listing screens as well as the details screen for a selected attraction. The latter shows the Park Map overview screen, where users can have a glance at all attractions and how they are located all over the theme park. The attractions can be toggled, allowing one also to see the theme park overview without attraction markers to help him navigate around.

Augmented Reality feature has also be incorporated into the application. Figure 5 depicts how location-based AR is implemented in the prototype application. By using the GPS sensor on the phone, the application tracks the device's location in real-time. To trigger the location-based AR, the user location must be nearby from an attraction. In other words, user location must be within the geofences created for that attraction. As an example, a target is set to the KFC Restaurant in the example shown in Figure 5.

When a user is $10 \mathrm{~m}$ or nearer from the restaurant, he will receive a notification that suggests the user visit the target restaurant. Once the user clicked on the notification, he will be brought to the AR screen where he will see a burger appearing as an AR object in the camera view. The prototype also provides a food ordering feature as a proof of concept - one can directly click on the burger object to begin food ordering. This feature will save visitors time to pre-order without entering first into the restaurant. 

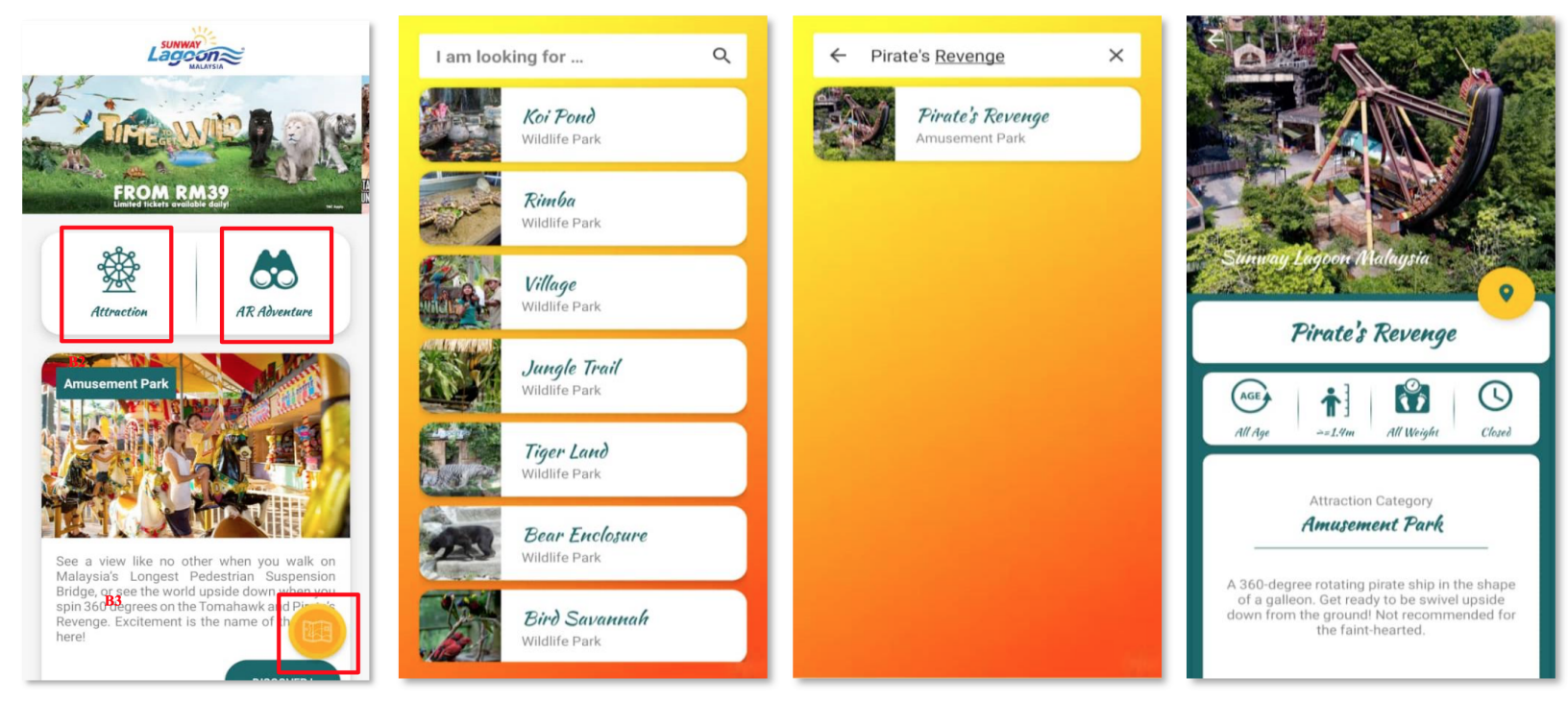

Figure 3: Main Screen and Listing of Attractions

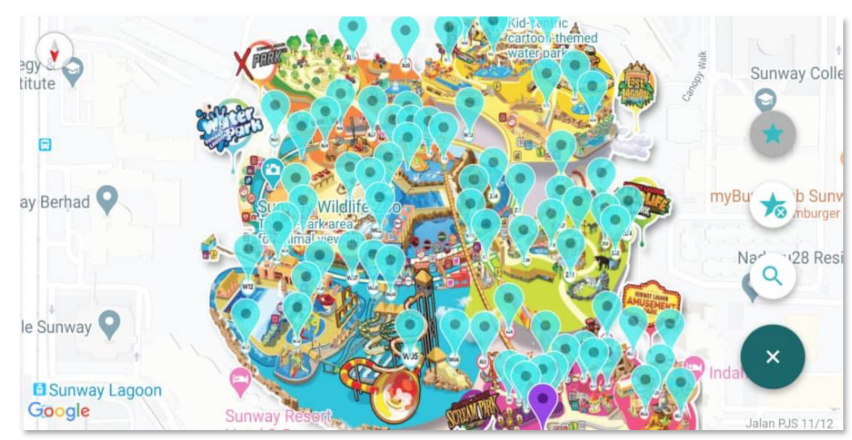

Figure 4: Park Map Overview with all Attraction Markers

\section{Evaluation and Discussion}

The evaluation of the prototype application was done through a test case and user acceptance testing (UAT). The test case consists of three different test units on the three main functions of the application - i.e. interactive map and attraction list, geofence notification and AR guide. The check on these main functions has been successful, and these functions are working as expected. For the UAT, 12 testers were recruited to evaluate the application by answering a survey. All testers were provided with the Android Package Kit (APK) file of the application.

Among all the questions asked in the survey, selected results related to the objectives of the paper - usability and user experience - are presented in this paper. $58.3 \%$ and $41.7 \%$ of the testers agree and strongly agree respectively that three main functions of the application are useful. When it comes to ease of use, $16.7 \%$ of the testers were neutral while the rest either agrees or strongly agrees. The majority $(91.7 \%)$ agrees and strongly agrees that the application will enhance their visiting experience at the theme park. Overall, the application has received very positive feedback as for its usefulness and ease of use. Hence, the user interface of the application, designed to be user-friendly and straightforward, is well received.

The survey also requested the testers to provide improvement suggestions. The suggestions are analysed and categorised in Table 1. However, there is feedback for the suggestion on improvement, which said that they prefer a step-by-step instruction to guide them on how to use the application correctly, especially for the AR guide function. The most complicated function is the AR guide, where it requires users to scan and detect fair surface from their environment. In this case, the application can be improved by adding a tutorial screen to teach the steps on how to use the AR function. The application can be improved by adding a panel to report on the system bugs or errors if the user faces any technical issues.

According to the result gathered from the user acceptance survey, majority of the respondents have a positive attitude towards the developed application. Besides, the application has high agreeableness from the survey question on functionality usefulness. The core functions of the application are interactive map, location-based push notification through geofencing and augmented reality guide, all of them are the location-aware and most-needed functions that a theme park application suitable to be adopted. For the first two functions, it is common to see in other existed theme park application.

For the AR guide function, it is a new idea for the theme park industry, and it has created a lot of potential values to attract their visitors. The mobile application is the best platform to engage visitors with the augmented reality, which gave them a different visiting experience. Some of the respondents reflect that they are interested in the app idea. They also suggest that the functionality can be improved by recommending point-of-interest in the park according to the user's location and integrating augmented reality contents 

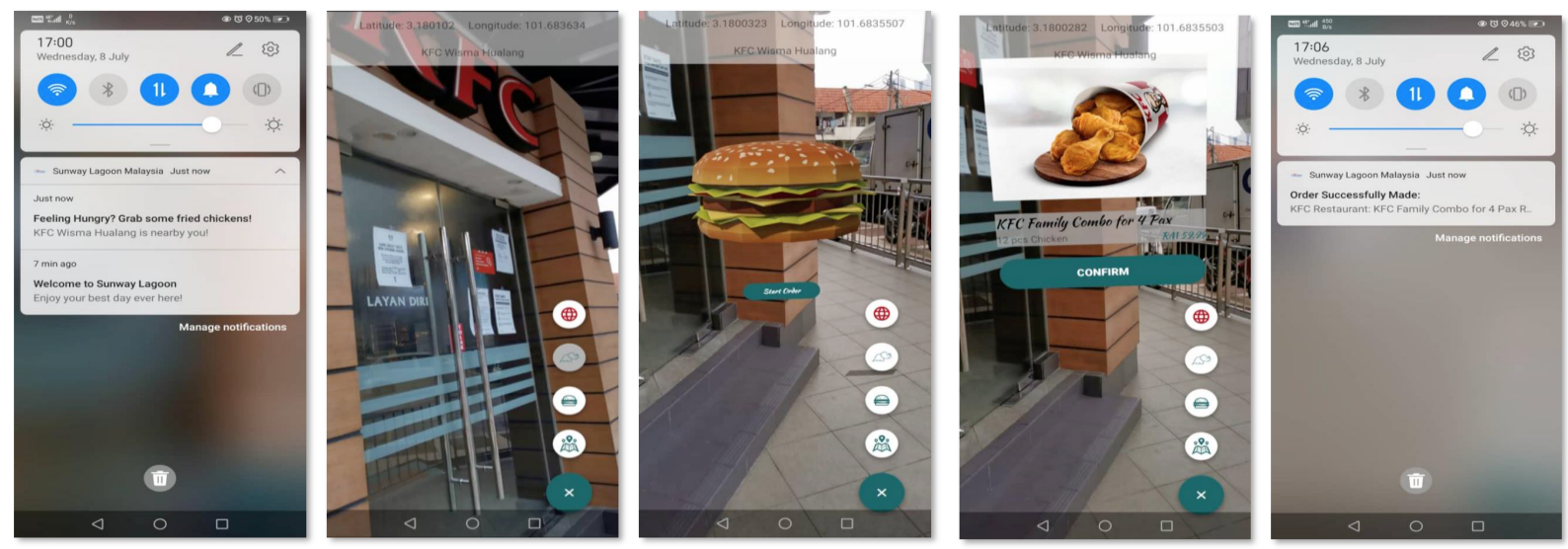

Figure 5: Location-based AR - Restaurant Menu and Ordering

\begin{tabular}{|c|c|c|}
\hline Category & Suggestion & Description \\
\hline Guidance & $\begin{array}{l}\text { Step-To-Step Instruction on } \\
\text { How to Use }\end{array}$ & $\begin{array}{l}\text { The application should present a step-to-step instruction to } \\
\text { guide users on how to use the app. }\end{array}$ \\
\hline \multirow[t]{2}{*}{ Location-Based Functions } & $\begin{array}{l}\text { Point of Interest (POI) Recom- } \\
\text { mendation }\end{array}$ & $\begin{array}{l}\text { The application should have a POI recommendation function } \\
\text { based on user location, ratings or comments from other } \\
\text { visitors. }\end{array}$ \\
\hline & Destination Guiding & $\begin{array}{l}\text { The application should guide users to a specific destination } \\
\text { through the map. }\end{array}$ \\
\hline \multirow[t]{2}{*}{ Schedule Management } & $\begin{array}{l}\text { Customised schedule planning } \\
\text { or tour plan for visitors }\end{array}$ & $\begin{array}{l}\text { The application should have a customised tour plan for dif- } \\
\text { ferent family size to optimise their time spending in the park. }\end{array}$ \\
\hline & Rides Estimated Waiting Time & $\begin{array}{l}\text { The application should provide an estimation of waiting time } \\
\text { for popular rides to save visitors time from waiting too long } \\
\text { in a queue. }\end{array}$ \\
\hline Cashless Park & Mobile Wallet & $\begin{array}{l}\text { The application should implement a mobile wallet which } \\
\text { enables visitors to be cashless in their in-park purchase. This } \\
\text { function is not recommended for Water Park as most of the } \\
\text { visitors do not carry their phones when they are having fun } \\
\text { in the water. }\end{array}$ \\
\hline \multirow[t]{2}{*}{ Internalisation } & Text-To-Speech Function & $\begin{array}{l}\text { The application should implement the text-to-speech func- } \\
\text { tion. This function is useful for those disabilities who have } \\
\text { difficulty typing. }\end{array}$ \\
\hline & Languages & $\begin{array}{l}\text { The application should support different languages to attract } \\
\text { foreigners. }\end{array}$ \\
\hline
\end{tabular}

TABLE 1: Summaries of Suggestions from the UAT

like displaying recommended information in the AR form with ratings and comments.

Most of the respondents think that it is enjoyable while experiencing the application and agree that the application will improve the visiting experience while they use the application in the park. Many respondents have given feedback on the functionality suggestions which can be adopted in the future. Some of them suggest that the location-based functionality can be improved by guiding or navigating users to a particular destination. Some of them focus their concern on the time management, where they wish to have functionalities such as showing the ride estimated time, schedule planning or customised tour plan to optimise their time spent in the park. This feedback is reasonable because typically, a visitor only spends one day or a few hours to experience the whole park.

Besides, some respondents suggest that they would like to see if the application can implement a ticket booking system in the app to enable the user to book or buy tickets directly from the app. They claimed that they are more attracted to the food discounts and vouchers which they can spend their in-park purchases more valuable. Some respondents suggest that the application can be improved by adopting a mobile wallet system, which enables visitors to have a cashless experience in the park. Other respondents say that they are expecting text-to-speech function or more languages selection for foreign visitors.

Lastly, from the survey questions on the willingness to adopt the application in their future visit, most of the respondents are willing to use this application if the theme park adopts the application when they revisit the theme park.

\section{Conclusion}

In conclusion, the produced prototype application has met the objectives of this project, where a location-based 
mobile application for theme park visitors is designed and developed. The results from the user acceptance survey also showed that the respondents are satisfied with the functions of the application and agree that the application will enhance the visitor experience, which met the objectives of this project. The possibility to allow visitors to interact with the application to find, locate and even make an order for food using AR intends to showcase how a visitor application can improve user experience.

The suggestions from the UAT will be the input for potential future work. Among the given suggestions, locationbased functions and schedule management can be seen as useful functions to be added because they help further improve the overall experience at a theme park. Also, it is important to think about a suitable strategy to attract visitors to download the application. Commonly, visitors only need the application when they are inside the park, and after their visits, they tend to uninstall the application. Ideas can be generated to encourage users to continue using the application so that they may return to the theme park soonest possible. In this way, the application can also become a marketing and engagement tool which will, in return, increase revenue.

\section{Acknowledgments}

The authors would like to thank the twelve testers who have tested the application and provided valuable feedback. The authors also wish to thank Sunway Lagoon management for supporting the research carried out within the scope of this project.

\section{References}

[1] X. Liu, H. H. Song, M. Baldi, and P. Tan, "Macro-scale mobile app market analysis using customized hierarchical categorization," in IEEE INFOCOM 2016 - The 35th Annual IEEE International Conference on Computer Communications, 2016, pp. 1-9.

[2] M. Iqbal, "App download and usage statistics (2019)," 2020, last accessed 16 September 2020. [Online]. Available: https://www.businessofapps.com/data/app-statistics/

[3] M. R. Islam and T. Mazumder, "Mobile application and its global impact," International Journal of Engineering \& Technology, vol. 10, pp. 72-78, 012010.

[4] D. Wang, S. Park, and D. R. Fesenmaier, "Mobile technology, everyday experience and travel," Travel and Tourism Research Association: Advancing Tourism Research Globally, 2016.

[5] J. Clement, "Market reach of the most popular android app categories worldwide as of september 2019," 2019, last accessed 16 September 2020. [Online]. Available: https://www.statista.com/statistics/200855/favouritesmartphone-app-categories-by-share-of-smartphone-users/

[6] _ - "Market reach of the most popular ios app categories worldwide as of september 2019," 2019, last accessed 16 September 2020. [Online]. Available: https://www.statista.com/statistics/270186/globalios-app-categories/

[7] I. P. Tussyadiah and D. Wang, “Tourists' attitudes toward proactive smartphone systems," Journal of Travel Research, vol. 55, no. 4, pp. 493-508, 2016. [Online]. Available: https://doi.org/10.1177/0047287514563168
[8] H. Antikainen, J. Rusanen, S. Vartiainen, M. Myllyaho, J. Karvonen, M. Oivo, and K. Laine, "Location-based services as tool for developing tourism in marginal regions," Nordia Geographical Publications, vol. 35 , no. 2, pp. 39-50, 2006

[9] K. MacKay and C. Vogt, "Information technology in everyday and vacation contexts," Annals of Tourism Research, vol. 39, no. 3, pp. 1380 - 1401, 2012. [Online]. Available: http://www.sciencedirect.com/science/article/pii/S0160738312000217

[10] P. Kourouthanassis, C. Boletsis, C. Bardaki, and D. Chasanidou, "Tourists responses to mobile augmented reality travel guides," Pervasive Mob. Comput., vol. 18, no. C, p. 71-87, Apr. 2015. [Online]. Available: https://doi.org/10.1016/j.pmcj.2014.08.009

[11] L.-L. Chang and K. F. Backman, "An investigation of creative tourists' experience and revisit intention," Travel and Tourism Research Association: Advancing Tourism Research Globally, 2016.

[12] T. Y. Lim, "Designing the next generation of mobile tourism application based on situation awareness," in 2012 Southeast Asian Network of Ergonomics Societies Conference (SEANES), 2012, pp. 1-7.

[13] T. R. Museum, "The railway museum app," 2020, last accessed 16 September 2020. [Online]. Available: https://play.google.com/store/apps/details?id=jp.railwayMuseumhl=en

[14] C.-H. Chou, "Location-based services for tourism - literature review," EXCEL International Journal of Multidisciplinary Management Studies, vol. 2, pp. 1-21, 022012.

[15] R. Roth, "Interactive maps: What we know and what we need to know," Journal of Spatial Information Science, vol. 6, pp. 59-115, 062013.

[16] Y.-g. Kim and W.-j. Kim, "Implementation of augmented reality system for smartphone advertisements," International Journal of Multimedia and Ubiquitous Engineering, vol. 9, pp. 385-392, 022014.

[17] I. Ilhan and E. Çeltek, "Mobile marketing: Usage of augmented reality in tourism," Gaziantep University Journal of Social Sciences, vol. 15, pp. 581-599, 122016.

[18] P. Pinto, M. Guerreiro, and J. Silva, "The tourist experience: Exploring the relationship between tourist satisfaction and destination loyalty," Tourism: An International Interdisciplinary Journal (sanda.corak@iztzg.hr); Vol.58 No.2, vol. 58, 012010. 